\title{
EL PLEBISCITO Y LOS DESAFÍOS POLÍTICOS DE CONSOLIDAR LA PAZ NEGOCIADA EN COLOMBIA
}

\author{
The 2016 Plebiscite and the Political Challenges of Consolidating \\ a Negotiated Peace in Colombia
}

\author{
SANDRA BOTERO* \\ Universidad del Rosario, Colombia
}

\section{RESUMEN}

Este artículo analiza los pormenores del proceso de paz entre el gobierno colombiano y las FARC durante el 2016, con énfasis en el antes y el después del plebiscito por la paz. Colombia y el mundo se sorprendieron cuando el No (rechazo a los acuerdos) superó al Sí (apoyo) por un muy estrecho margen. ¿Cómo entender este resultado? Es necesario ubicarse en la intersección de lo estructural con lo político para comprender lo sucedido. Primero, resalto la importancia de algunas características sociodemográficas que emergen de los análisis de la votación a nivel municipal. Conecto estos patrones estructurales con la dinámica de la campaña política previa a la votación. Finalmente, discuto las implicaciones políticas del plebiscito y los desafíos que impuso a la implementación de los acuerdos.

Palabras clave: proceso de paz, Colombia, plebiscito por la paz

\begin{abstract}
This article analyzes key moments of the peace process between the Colombian government and the FARC during 2016. Colombia and the world were shocked when voters narrowly rejected the peace accords in a national plebiscite. What explains these electoral results? I argue that it is necessary to incorporate structural and political elements into our efforts to understand what happened in October of 2016. I emphasize the importance of sociodemographic patterns at the municipal level and connect these with the dynamics of the political campaign leading up to the vote. In the last section I discuss the political implications of the plebiscite and the challenges that it entails for the implementation of the peace accords.
\end{abstract}

Key words: peace process, Colombia, plebiscite

Agradezco a Juan Albarracín y a Lucía Tiscornia sus sugerencias y su generosa ayuda construyendo las gráficas y a Néstor Castañeda, Héctor Botero, Álvaro Quezada y Santiago Quintero sus comentarios a versiones anteriores. También agradezco al Kellogg Institute de la Universidad de Notre Dame, y especialmente a Denise Wright, por facilitar el espacio en el cual desarrollé estas ideas. 


\section{INTRODUCCIÓN}

En septiembre de 2016, tras varios años de negociaciones, el gobierno de Juan Manuel Santos y las FARC-EP (Fuerzas Armadas Revolucionarias de Colombia) firmaron acuerdos de paz. Con la firma se dio inicio al proceso de desarme y desmovilización de la guerrilla más antigua del continente americano, fundada en 1964. La refrendación popular de los acuerdos vía plebiscito, programada para unas semanas después, estaba prevista como el primer paso del cronograma de implementación. Colombia y el mundo se sorprendieron cuando el 2 de octubre el No (rechazo) superó al Sí (apoyo) por un estrecho margen de menos de un punto porcentual, dejando a los acuerdos de paz en vilo. La victoria del No en el plebiscito fue un punto de quiebre: ¿cómo entender este resultado electoral? ¿Cuáles han sido sus implicaciones políticas? Los colombianos no rechazaron uniformemente la paz: para entender el No es imprescindible estudiar los patrones de votación y la corta pero intensa campaña previa. El proceso de paz siguió adelante, pero la no refrendación popular de los acuerdos alteró su rumbo y ha tenido efectos significativos en la política nacional.

Este artículo se enfoca exclusivamente en analizar los pormenores del proceso de paz colombiano durante 2016, con énfasis en el antes y el después del plebiscito. A manera de introducción al análisis de los resultados electorales, hago primero un breve recuento de la estructura de las negociaciones de paz, recogiendo momentos centrales del cronograma que culminó en el cierre de las negociaciones en 2016. En la tercera sección discuto las implicaciones políticas del plebiscito y los desafíos que este impuso a la implementación de los acuerdos. La sección final concluye.

\section{EL LARGO CAMINO A LA CULMINACIÓN DE LAS NEGOCIACIONES}

El proceso de paz se inició a principios de 2012 con una fase exploratoria y secreta de acercamientos iniciales entre el gobierno y las FARC. En agosto de ese mismo año, las partes anunciaron públicamente un acuerdo que planteaba las reglas de juego y una agenda de negociación. Las negociaciones se realizaron en La Habana, Cuba, a lo largo de los siguientes cuatro años; durante este tiempo, los equipos negociadores de la guerrilla y el gobierno colombiano discutieron uno a uno y a puerta cerrada una serie de acuerdos temáticos. La metodología que escogió el equipo de Santos fue, a grandes rasgos, la siguiente: avanzar a partir de una agenda claramente predefinida, resultado de un acuerdo previo entre los dos equipos negociadores; trabajar fuera de Colombia bajo confidencialidad, con acceso restringido para los medios de comunicación; y no llegar al cese al fuego bilateral sino hasta que concluyesen las negociaciones. 
Estas determinaciones buscaban proteger a este proceso de paz de los errores que contribuyeron al fracaso de otros intentos anteriores. ${ }^{1}$

En mayo de 2013 los equipos negociadores anunciaron el logro del primer acuerdo temático, el agrario. La lógica de construcción de los acuerdos fue incremental, módulo por módulo, haciendo hincapié en que la paz solo se firmaría cuando el texto completo estuviera listo. En palabras de Humberto de La Calle, jefe de la delegación del gobierno: "Nada está acordado hasta que todo esté acordado" (Urna de Cristal 2013). Una vez terminadas las negociaciones y firmada la paz se presentaría el paquete final y completo al electorado colombiano para que lo conociera y aprobara vía plebiscito. Desde el primer momento el gobierno controló fuertemente el flujo de información sobre los avances del proceso en La Habana, distribuyendo información a través de comunicados y voceros autorizados única y exclusivamente. Tras un año y medio de negociaciones, en noviembre de 2013, se anunció el segundo acuerdo, sobre participación política. En mayo del año siguiente las partes llegaron a un acuerdo sobre la superación de cultivos ilícitos, y en junio, se anunció la creación de dos subcomisiones: la técnica, sobre el fin del conflicto (que comenzaba a discutir propuestas para el proceso de desmovilización, desarme y reintegración) y la de género (encargada de incluir el enfoque de género en los acuerdos). ${ }^{2}$ En agosto de 2014 se creó la Comisión Histórica del conflicto y las víctimas, y empezaron las visitas de representantes de las víctimas a la mesa de negociaciones de La Habana. En diciembre de ese mismo año, las FARC declararon un cese al fuego unilateral e indefinido.

El año 2015 fue particularmente difícil para el proceso, como bien lo anotaron Wills Otero y Hoyos (2016) en su artículo en esta revista el año pasado: la ruptura de la tregua y los enfrentamientos entre el ejército y algunos frentes guerrilleros generaron mucha tensión. Paralelo a las dificultades sobre el terreno, la mesa de negociación en Cuba también atravesó momentos tensos al abordar temas particularmente espinosos: las discusiones sobre víctimas y justicia transicional. En medio de creciente controversia, a mediados de 2015 la mesa anunció el acuerdo sobre comisión de la verdad, la convivencia, la no repetición y en agosto se anunció el acuerdo sobre la Jurisdicción Especial para la Paz (JEP),

1 Desde 1980, diez intentos de procesos de paz con las FARC y con otros grupos alzados en armas han sucedido en Colombia. Aunque otros gobiernos llegaron a acuerdos con otras organizaciones (por ejemplo, Virgilio Barco con el M-19, el Quintín Lame y una facción del EPL; Álvaro Uribe con organizaciones paramilitares) el gobierno de Santos ha sido el único en lograr firmar un acuerdo con las FARC, la más importante organización armada del país. Un breve recuento periodístico de esta historia puede consultarse en López Montaño y Cueter (2016); para un análisis más a fondo, véase Pizarro Leongómez (2017).

2 La creación de la subcomisión de género fue resultado de la solicitud de diferentes sectores y organizaciones de mujeres que empezaron a organizarse después del nombramiento del equipo negociador del gobierno que, originalmente, solo incluía hombres. Esta subcomisión revisó los acuerdos a los que se había llegado hasta el momento y participó en discusiones posteriores para incorporar medidas concretas que ayudasen a superar la desigualdad y exclusión. Según el equipo de paz del gobierno, "se trata de abordar de manera concreta en varios de los temas de los acuerdos, los problemas de fondo de las mujeres en el campo, en la participación política, en el impacto que tiene sobre ellas la violencia causada por el flagelo de las drogas ilícitas, de sus problemas como víctimas y de los riesgos que han enfrentado en el conflicto y los que podrán enfrentar en una etapa de post conflicto" (Alto Comisionado para la Paz 2016, 23 de julio). 
que contiene los puntos centrales del marco jurídico para la verdad, la justicia, la reparación y la no repetición del conflicto. La JEP estará conformada por magistrados nacionales y extranjeros y tendrá su propio cuerpo investigativo. ${ }^{3}$ Una vez creada y escogidos sus jueces, a la JEP acudirán los miembros de las FARC desmovilizados, los civiles, uniformados y los agentes del Estado que estén involucrados o relacionados con faltas por motivo del conflicto armado.

El 2016, el cuarto año de las negociaciones, arrancó entonces con dos grandes pendientes sobre la mesa: por un lado, la definición de detalles importantes sobre el fin del conflicto y, por el otro, la refrendación popular de los acuerdos. La firma de los acuerdos se había programado para marzo de ese año pero el cronograma tuvo que reajustarse para dar más tiempo a la discusión de la dejación de armas, el proceso de reinserción y las zonas de ubicación (lugares donde las FARC se ubicarían de manera transitoria durante el proceso de desmovilización). Mientras estas discusiones se daban, la controversia sobre los detalles de la JEP se hizo particularmente aguda. Para algunos de sus críticos, la JEP es demasiado poderosa; para sus detractores (un grupo importante) este marco jurídico no es otra cosa que garantía de impunidad para las FARC.

Paradójicamente, las críticas al proceso de paz se hicieron especialmente fuertes al tiempo que empezaron a verse resultados incontrovertibles como la disminución drástica de los enfrentamientos y el número de muertos asociados con el conflicto interno. El Gráfico 1 muestra una tendencia a la baja en las muertes asociadas al conflicto con las FARC a lo largo del proceso de paz. En el lado derecho de la gráfica se puede ver que una vez que las negociaciones entraron en su etapa final, las muertes de civiles bajaron a cero. El gobierno no supo o no pudo comunicar estos avances a la opinión pública y, por lo tanto, muchos colombianos no registraron esto como un resultado positivo consecuencia directa del avance de las negociaciones.

Un resumen breve de sus características principales está disponible en el documento "P\&R [Preguntas y respuestas]: Jurisdicción Especial para la Paz" redactado por el Alto Comisionado para la Paz. Ese texto, así como el texto completo de los acuerdos de paz, están disponibles en el sitio web del Alto Comisionado para la Paz: http://equipopazgobierno.presidencia.gov.co 
Gráfico 1. Muertes de civiles, de la fuerza pública y de las FARC en eventos de conflicto con participación directa de las FARC 2010-2017

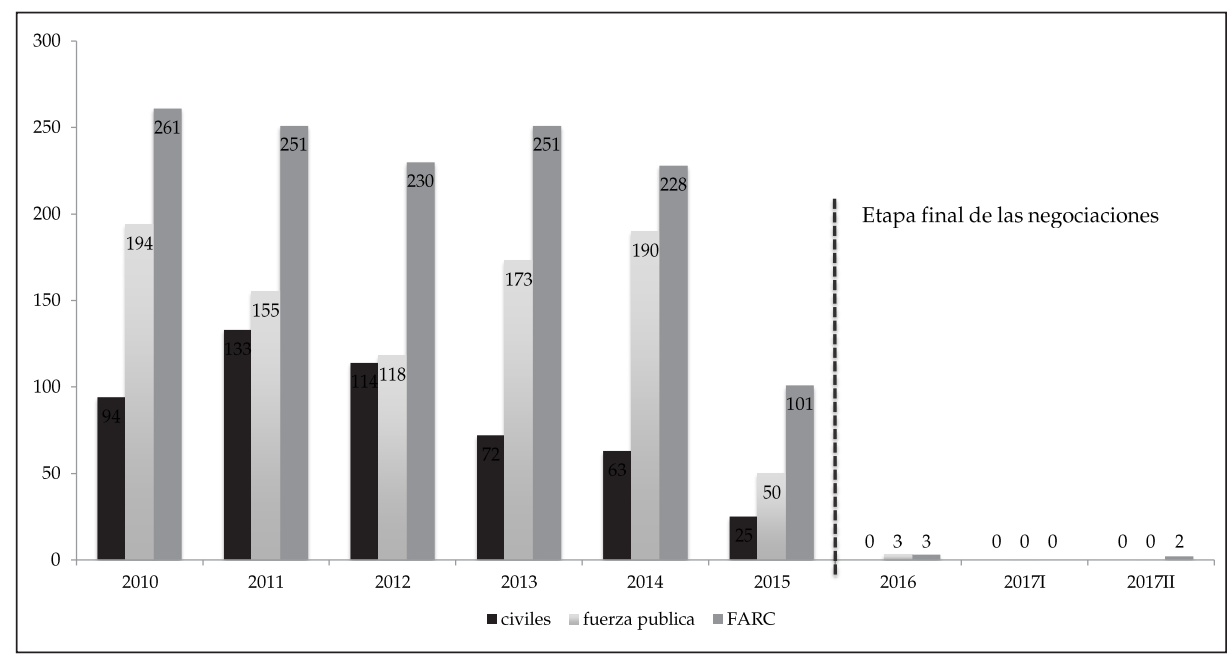

Datos a mayo de 2017

Fuente: Centro de Recursos para el Análisis de Conflictos (CERAC)

La culminación de las negociaciones y la refrendación popular de los acuerdos se sucedieron en un corto lapso en la segunda mitad de 2016, tras varios años de diálogos herméticos y una etapa final que, como vimos, fue controversial. Septiembre y octubre, en especial, fueron meses muy movidos. En septiembre, se celebró la última conferencia de las FARC, se anunció el cese al fuego bilateral y se firmaron los acuerdos en una fastuosa ceremonia en Cartagena. El tono celebratorio de este evento daba casi por sentado que el resultado en las urnas sería la aprobación de los acuerdos.

El 2 de octubre, a solo días del megaevento en Cartagena, se llevó a cabo el plebiscito por la paz. Los colombianos fueron llamados a las urnas para responder "sí" o "no" a la pregunta: ¿Apoya el acuerdo final para terminación del conflicto y construcción de una paz estable y duradera? Ni el equipo de gobierno, con el Sí, ni los partidarios del No, vieron venir la victoria electoral de esta última opción.

\section{POR QUÉ LA VICTORIA DEL NO EN EL PLEBISCITO POR LA PAZ ${ }^{4}$}

La victoria del No fue muy apretada: superó al Sí por apenas $0,43 \%$ del total de los votos con $62 \%$ de abstencionismo. ${ }^{5}$ En los días y semanas que siguieron al 2

4 Esta segunda sección reproduce algunos apartados breves de un texto mío, “Colombianos divididos ante la paz" (Botero 2016). Tomo algunas de las ideas esbozadas allí, pocos días después del plebiscito, como punto de partida para un nuevo análisis, más profundo y actualizado.

5 Los resultados del plebiscito pueden consultarse en el sitio web de la Registraduría Nacional de Colombia: http://plebiscito.registraduria.gov.co 
de octubre, diversos analistas colombianos aportaron insumos para empezar a comprender estos resultados. Podemos dividir estos elementos de análisis para la victoria del No en dos grupos: de un lado, están quienes hicieron hincapié en factores estructurales como pobreza, inequidad, la división urbano/rural, presencia estatal e incidencia del conflicto. De otro lado, están los análisis que pusieron el acento en elementos más políticos y de corte coyuntural como determinantes - por ejemplo, las maquinarias electorales o la importancia del uribismo- Está claro que no hay una única y fácil explicación para lo sucedido. Considero que es necesario pararse en la intersección de lo estructural con lo político para entender qué pasó con el plebiscito. Para avanzar en esa dirección, comienzo por hacer una síntesis que resalta algunas características sociodemográficas clave que emergen de los análisis descriptivos de la votación a nivel departamental y municipal. Mi interés es conectar estos patrones macro con las dinámicas políticas más circunstanciales. En el apartado final pongo el acento en la importancia de la campaña política previa a la votación.

Empecemos por el abstencionismo. El 62\% de abstencionismo observado en el plebiscito no es inaudito, aunque sí es más elevado que las tasas de abstencionismo en elecciones recientes. El promedio de abstencionismo en las elecciones legislativas entre 1991 a 2014 fue del $56 \%$ y las elecciones presidenciales presentan una tendencia similar, con un promedio de abstencionismo del $54 \%$ entre 1990 y 2014 (cálculos propios basados en datos publicados en Caicedo Ortiz 2015). ${ }^{6}$ El 62\% es ciertamente preocupante —en general, y dada la importancia de esta votación en particular- pero no está fuera de norma. En cualquier caso, el abstencionismo es a menudo más pronunciado en las regiones y probablemente se inscribe en el contexto más amplio de la crisis de satisfacción con la democracia y sus instituciones representativas, fenómeno que Rodríguez Raga explora en su análisis sobre Colombia en este mismo volumen. Si bien el umbral aprobatorio del plebiscito era bajo (13\% del padrón electoral, poco más de 4,5 millones de votos), dado este historial, llevar votantes a las urnas era un reto tanto para los partidarios del Sí como para los del No. Aunque es necesario tener cuidado al hacer inferencias causales basadas en datos agregados, hay razones para creer que los partidarios del No tuvieron más éxito que los del Sí en movilizar votantes. Entre ellas, está que el promedio de abstencionismo en los departamentos donde se impuso el Sí fue diez puntos más alto que el promedio de abstencionismo en los departamentos donde ganó el No (69\% y $59 \%$ respectivamente) y que una diferencia similar se observa a nivel municipal.

Un factor que muchos consideran de peso es la división urbano/rural. Un primer vistazo al mapa electoral del plebiscito a nivel departamental muestra un patrón sobre el que otros han llamado la atención: las zonas donde se impuso el No (gris claro en el Gráfico 2) coinciden, a grandes rasgos, con las zonas más urbanas y más densamente pobladas de Colombia. La capital Bogotá y el

Según Caicedo Ortiz (2015), en los tres períodos más recientes el abstencionismo en las elecciones legislativas se estabilizó entre $54-56 \%$ y estuvo entre $50-53 \%$ para las presidenciales. 
departamento de Boyacá son la excepción; allí el Sí se impuso con el 56\% y poco más del $50 \%$ respectivamente.

Gráfico 2. Resultados plebiscito 2016 a nivel departamental

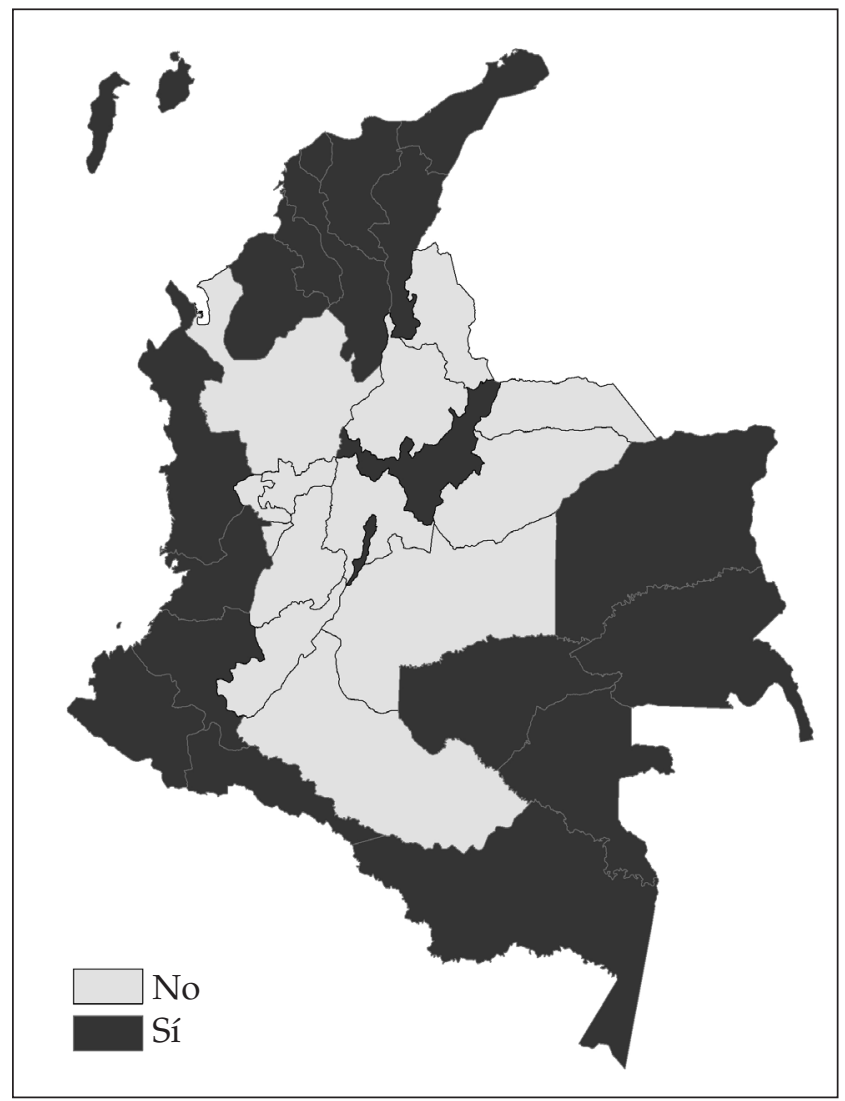

Fuente: Basado en datos de la Registraduría Nacional

Conviene matizar esta impresión inicial desagregando aún más los patrones geográficos y explorando las dinámicas en el siguiente nivel administrativo, el municipal. Varios analistas coinciden en señalar que los municipios donde el Sí se impuso son (en su mayoría) más pobres, más afectados por el conflicto, más desiguales y más alejados de la presencia efectiva del Estado. ${ }^{7}$ Según Muñoz y Herreño (2016), por ejemplo: "Para ser más precisos, el Sí ganó en el 86\% de los municipios más pobres, en el $67 \%$ de los municipios con más acciones violentas, y en el $62 \%$ de los municipios más desiguales." El No, en contraste,

Los análisis de Fergusson y Molina (2016), Muñoz y Herreño (2016) y Álvarez Vanegas y Garzón Vergara (2016) combinan los datos electorales de la Registraduría Nacional con otros indicadores, llegando a conclusiones interesantes. 
se impuso en los municipios más integradas a los centros urbanos, con mayor acceso, "donde las instituciones están y funcionan mejor" (Álvarez Vanegas y Garzón Vergara 2016).

Esto, sin embargo, no significa que el país urbano haya votado todo por el No. Dado que Colombia es un país de ciudades medianas, con $74 \%$ de habitantes urbanos, resulta esclarecedor estudiar brevemente los patrones de votación en las principales ciudades. Si el No fuese un fenómeno netamente urbano esperaríamos victorias en un número significativo de las ciudades importantes. La Tabla 1 clasifica las 19 ciudades colombianas con más de 300.000 habitantes según tres grupos: aquellas donde el Sí se impuso con una ventaja superior al $55 \%$, aquellas donde el No se impuso con más de 55\% y aquellas de "victorias reñidas", donde la diferencia entre las dos opciones fue de menos de cinco puntos porcentuales. Juntas, estas 19 ciudades componen la mitad de la población nacional. La Tabla 1 demuestra claramente que no hay un patrón claro de apoyo al No o al Sí a nivel de las principales ciudades. Un tercio fueron victorias reñidas, y muy pocas fueron ventajas absolutas. La tabla aporta otro dato que habla a favor de la capacidad de movilización del No: en 5 de las 6 ciudades en las cuales el No se impuso (Medellín, Villavicencio, Cúcuta, Ibagué y Bello), lo hizo por un margen superior al $60 \%$. Esto sugiere que en las ciudades principales donde ganó, el No tuvo victorias más contundentes.

Tabla 1. Resultados del plebiscito por la paz en las principales ciudades colombianas (\% de la votación total opción ganadora)

\begin{tabular}{|c|c|c|c|c|c|}
\hline \multicolumn{2}{|c|}{$\begin{array}{l}\text { Ciudades donde el Sí se impuso } \\
\text { con más del } 55 \%\end{array}$} & \multicolumn{2}{|c|}{$\begin{array}{l}\text { Ciudades donde el No se } \\
\text { impuso con más del 55\% }\end{array}$} & \multicolumn{2}{|c|}{$\begin{array}{l}\text { Ciudades con victorias } \\
\text { reñidas (entre el } 50 \text { y el } 54.9 \% \text { ) }\end{array}$} \\
\hline Barranquilla & $57 \%$ & Medellín & $63 \%$ & Valledupar & $51 \%(\mathrm{Si})$ \\
\hline Bogotá & $56 \%$ & Villavicencio & $64 \%$ & Santa Marta & $53 \%(\mathrm{Si})$ \\
\hline Cartagena & $55 \%$ & Cúcuta & $65 \%$ & Cali & $54 \%(\mathrm{Si})$ \\
\hline Pasto & $62 \%$ & Bucaramanga & $55 \%$ & Manizales & $51 \%(\mathrm{No})$ \\
\hline Soledad & $59 \%$ & Ibagué & $60 \%$ & Montería & $52 \%(\mathrm{No})$ \\
\hline \multirow[t]{2}{*}{ Buenaventura } & $70 \%$ & Bello & $63 \%$ & Soacha & $52 \%(\mathrm{No})$ \\
\hline & & & & Pereira & $54 \%(\mathrm{No})$ \\
\hline
\end{tabular}

Fuente: Elaboración propia con datos de la Registraduría Nacional

El minúsculo margen de diferencia entre el Sí y el No a nivel nacional, margen que se replicó en varias de las ciudades principales, y en otros niveles subnacionales, denuncia una fuerte polarización. Esta polarización no puede entenderse únicamente en relación con los acuerdos de paz, como veremos a continuación. El plebiscito fue una votación atípica, con una campaña previa muy corta de solo semanas. No obstante su brevedad, la campaña fue esencial. Los aciertos y desaciertos de los partidarios del Sí y del No en las semanas antes 
del 2 de octubre de 2016 amarraron la aprobación de los acuerdos de paz, de por sí un tema controversial, a otras discusiones polémicas. Los partidarios del No movilizaron a sus adeptos de manera estratégica y emotiva convirtiendo al plebiscito en un referendo sobre la gestión del presidente Santos y vinculándolo con temas clave para la derecha conservadora (como la defensa de la familia tradicional), que no estaban directamente relacionados con los acuerdos. Los partidarios del Sí se confiaron y no lograron articular una campaña efectiva. Veamos por qué.

La paz es un objetivo loable, pero eso no significa que la victoria electoral del Sí estuviera segura. El presidente Santos insistió desde el principio de las negociaciones en la refrendación electoral para legitimar los acuerdos de cara a su implementación. Aunque la refrendación popular tenía potencial político, era al mismo tiempo una estrategia de muy alto riesgo. Los acuerdos negociados que buscan poner fin a conflictos internos complejos como el colombiano son por naturaleza controversiales. En Colombia, y en muchos otros países, estos acuerdos suelen incluir, por ejemplo, disposiciones sobre penas reducidas y participación política de los desmovilizados, medidas que no necesariamente cuentan con el apoyo de las mayorías. Someter a votación estos temas es una apuesta arriesgada que pone en peligro innecesario el fruto de negociaciones arduas. Usualmente los acuerdos se ratifican por el Ejecutivo o por la vía del Congreso, bajo la lógica de que estas instituciones tienen mandato popular. ${ }^{8}$ Teniendo en cuenta que las encuestas arrojaban resultados contradictorios y que en la etapa final de las negociaciones alrededor del 50\% de los colombianos no apoyaba el proceso de paz (ver Gráfico 7 en Rodríguez Raga en este volumen, Liendo y Braithwaite 2016), la importancia de la estrategia de campaña de ambos bandos se hace aún más evidente.

Francisco Gutiérrez, uno de los pocos analistas que pusieron sobre la mesa la factibilidad de la victoria del No antes del plebiscito, hace énfasis en la importancia del uribismo para entender lo sucedido. Gutiérrez distingue entre dos elementos en especial: el carácter personalista del uribismo y su fuerza como maquinaria electoral en las zonas donde tiene arraigo (Semana 2016, 8 de octubre). El uribismo gira exclusivamente alrededor de su máximo líder, el expresidente y actual senador de la república Álvaro Uribe. El expresidente Uribe, quien se opuso a los acuerdos de paz desde un principio, es el líder de la derecha colombiana, un político inmensamente popular que fue jefe natural de la campaña por el No. Su enemistad con Juan Manuel Santos, quien fuera miembro de su gabinete, es bien conocida. Como líder político del No, Uribe buscó, primero, acabar con las negociaciones. Alistándose para el plebiscito, sus partidarios cerraron filas en apoyo a su postura, capitalizando sobre su arrastre personal y su alta popularidad. En la etapa inmediatamente posterior

\footnotetext{
De hecho, una revisión de los mecanismos de ratificación de 51 acuerdos de paz firmados entre 1989 y 2014, y registrados en la base de datos de procesos de paz del Instituto Kroc de la Universidad de Notre Dame, The Peace Accord Matrix, muestra que ninguno de esos acuerdos tiene como mecanismo de ratificación el voto popular. Véase http:// peaceaccords.nd.edu
} 
al plebiscito, Uribe se insertó en la renegociación del acuerdo y continuó oponiéndose a su implementación.

Los partidarios del No diseñaron una campaña que buscaba generar rechazo e indignación. En una entrevista días después del plebiscito, el jefe de campaña del No, Juan Carlos Vélez, fue claro al decir: "Estábamos buscando que la gente saliera a votar verraca [enfurecida]", y explicó la premisa central de la campaña, sugerida por asesores extranjeros, así: "Ellos [los del Sí] van a apelar a la esperanza. Ustedes [los del No] tienen que apelar a la indignación. Dejen de explicar los... acuerdos (...)".${ }^{9}$ El objetivo era movilizar votos de manera emotiva, vinculando los acuerdos y el Sí con ítems polémicos de la agenda política que eran particularmente relevantes para ciertos grupos. Los temas clave fueron, entre otros, la gestión del presidente Santos (cuyos índices de aprobación han venido en declive, ver Gráfico 1 en el texto de Rodríguez Raga en este volumen), la reforma tributaria que se discutía por esos días en el Congreso y el enfoque de género como un ataque a la familia tradicional.

Buscando generar rechazo a los acuerdos, el equipo del No diseñó campañas muy mediáticas, enfatizando un tema u otro según la audiencia. En más de una ocasión se echó mano a la retórica inflamatoria y a datos distorsionados. Los ataques al enfoque de género de los acuerdos ilustran bien la táctica: en llave con sectores conservadores y de derecha, los partidarios del No hicieron una lectura tendenciosa del enfoque de género y enfatizaron esto como problema frente a las audiencias de fieles de iglesias cristianas. En el contexto de la campaña por el No se difundió información falsa y se describió dicho enfoque como una "imposición de la ideología de género". Por ejemplo, una pancarta de campaña leía: "No al aborto/No a quienes atacan la familia/No al enfoque de género/ Por eso digo No a los acuerdos de La Habana". El objetivo era que los votantes, especialmente los cristianos y los más conservadores, asociaran los acuerdos con la controversia política frente al aborto y el matrimonio igualitario. Esto fue una distorsión del espíritu y propósito del enfoque de género: los acuerdos de paz colombianos son pioneros en el mundo en su incorporación de medidas específicas para mitigar los efectos diferenciados del conflicto armado en las mujeres y para propender por la igualdad durante el postconflicto.

\footnotetext{
En medio del escándalo tras la entrevista dada al diario La República, Vélez tuvo que renunciar al Centro Democrático, el partido uribista. Las declaraciones de Vélez son muy elocuentes; aquí un aparte: “Descubrimos el poder viral de las redes sociales. Por ejemplo, en una visita a Apartadó, Antioquia, un concejal me pasó una imagen de Santos y 'Timochenko' [líder de las FARC] con un mensaje de por qué se le iba a dar dinero a los guerrilleros si el país estaba en la olla [bancarrota]. Yo la publiqué en mi Facebook y al sábado pasado tenía 130.000 compartidos con un alcance de seis millones de personas. Hicimos una etapa inicial de reactivar toda la estructura del Centro Democrático en las regiones repartiendo volantes en las ciudades. Unos estrategas de Panamá y Brasil nos dijeron que la estrategia era dejar de explicar los acuerdos para centrar el mensaje en la indignación. En emisoras de estratos medios y altos nos basamos en la no impunidad, la elegibilidad y la reforma tributaria, mientras en las emisoras de estratos bajos nos enfocamos en subsidios. En cuanto al segmento en cada región utilizamos sus respectivos acentos. En la Costa individualizamos el mensaje de que nos íbamos a convertir en Venezuela. Y aquí el No ganó sin pagar un peso. En ocho municipios del Cauca pasamos propaganda por radio la noche del sábado centrada en víctimas" (Vélez, citado en La República 2016).
} 
Otro tema candente durante la campaña previa al plebiscito fue el régimen pensional, alrededor del cual circuló información falsa. Algunos partidarios del No difundieron la idea que los acuerdos afectarían el régimen pensional perjudicando a los ya pensionados o a punto de pensionarse. La representante María Fernanda Cabal, por ejemplo, sugirió en televisión que de ganar el Sí los pensionados perderían el 7\% de su pensión (Semana 2016, 19 de diciembre). Esto no era cierto: los acuerdos no hacen ninguna modificación al sistema pensional. Otros spots publicitarios y material circulado en redes sociales (especialmente en la costa atlántica) aseguraban que la firma de los acuerdos conllevaba el cambio de modelo político a una dictadura idéntica al régimen "castrochavista" venezolano, afirmación errónea (Semana 2016, 19 de diciembre). Al admitir una demanda ciudadana a los resultados electorales, el Consejo de Estado (máximo tribunal administrativo) discutió evidencia de publicidad electoral que calificó como engañosa y afirmó que los promotores del No les mintieron a los colombianos: “La información que se suministró al electorado en la fase definitiva de campaña reflejó una total tergiversación, en muchos de sus aspectos neurálgicos, del contenido del acuerdo sometido a votación el 2 de octubre de 2016" (El Colombiano 2016, 19 de diciembre). Distorsionando y tergiversando, los estrategas del No polarizaron el debate y lo llevaron lejos del propósito de los acuerdos, la paz negociada.

Esta estrategia de campaña se benefició, además, de las condiciones de confidencialidad que caracterizaron los cuatro años de negociación. Como ya se mencionó, la decisión de negociar en Cuba, a puerta cerrada, buscaba blindar el proceso de intentos de sabotaje, y mitigar así los errores de negociaciones anteriores. Este hermetismo impidió que el público colombiano conociera las condiciones que se estaban negociando sino hasta las fases finales de las conversaciones. El contexto fue caldo fértil para la especulación, la falta de claridad sobre el contenido e hizo difícil desvirtuar inequívocamente estas acusaciones desde más temprano.

En marcado contraste con la efectiva y afectiva campaña del No (impulsada por el uribismo) los partidarios del Sí cometieron una serie de errores estratégicos y no lograron movilizar al mismo nivel ni conectarse de manera tan efectiva con sus grupos de apoyo. La campaña del Sí empezó tarde y esto tuvo serias consecuencias. El tiempo de campaña oficial para el plebiscito fue muy breve; poco más de un mes. La demora se debió en gran parte a que el gobierno no quería arrancar oficialmente hasta que la Corte Constitucional no fallase aprobando los acuerdos, un paso previo necesario. Mientras el gobierno esperaba el fallo, el No ya se estaba movilizando. Este retraso de semanas le costó al Sí en posicionamiento mediático, coordinación y contundencia. Además, el equipo del Sí se confió en la victoria, probablemente en parte porque las encuestas sobre intención de voto variaron mucho inicialmente (Caracol 2016) y al final les daban la ventaja.

La campaña del Sí tenía como espina dorsal explicar los acuerdos y venderlos como "los mejores posibles". El mensaje no se transmitió de forma que fuese 
un contrapeso efectivo ante la carga emocional que puso el No. Andrei Gómez Suárez (Semana 2016, 23 de diciembre) señala que la campaña del gobierno fue racional, intentando explicar de manera racional el proceso y los pro y los contra de lo negociado. Se quedó corta frente a la estrategia emocional del No, que le apostó a la indignación y la rabia, con un líder popular y personalista como Uribe de vocero. Adicionalmente, la maquinaria electoral de los partidos de la coalición de gobierno (la Unidad Nacional, con el presidente Santos) falló. La Silla Vacía (2016, 3 de octubre) reportó errores diversos y graves en los días previos al plebiscito: falta de coordinación y falta de recursos para movilizar votantes, entre otras.

Podemos aproximarnos a las diferencias en el desempeño de ambas campañas volviendo sobre los patrones agregados de votación del plebiscito en 2016, y comparándolos con resultados electorales anteriores; en este caso, las elecciones presidenciales de 2014. La segunda ronda de las elecciones presidenciales de 2014 en las que Juan Manuel Santos (candidato por la Unidad Nacional) se enfrentó a Oscar Iván Zuluaga (candidato uribista) fueron, a final de cuentas, un referendo sobre la continuación de las negociaciones de paz. La victoria sobre Zuluaga, quien cuestionaba fuertemente el proceso de paz, le dio a Santos el mandato para continuar los diálogos en La Habana. En este sentido, podemos asumir que un eje central de las dos elecciones - el proceso de paz- era el mismo y que las dos fuerzas políticas que se enfrentaron en la segunda ronda presidencial en 2014, Unidad Nacional y Partido de la U, eran similares a las que hicieron campaña por el Sí y el No en el 2016, respectivamente. La Unidad Nacional que apoyó a Santos en su reelección apoyó en su mayoría al Sí, y el uribismo era el corazón de la campaña por el No. Bajo estas premisas, el número de votos logrados por cada una de estas dos coaliciones (Santista y Uribista) en 2014 y 2016 es comparable y puede darnos luces sobre si cada coalición logró movilizar más, menos o igual número de votantes en 2016 (plebiscito) en comparación con los votos logrados en 2014 (presidenciales).

Para comparar el desempeño electoral de los dos bloques calculé la diferencia en el número de votos para cada una de las dos coaliciones (Santista y Uribista) en el plebiscito y en las elecciones presidenciales en los nueve departamentos con mayor número de votantes habilitados y la capital. Incluyo la diferencia en el número de sufragantes para dar una idea, aunque imperfecta, del cambio en el nivel de abstencionismo (columna gris oscuro en el Gráfico 3). El Gráfico 3 presenta las diferencias en el número absoluto de votos a favor del Santismo (gris claro) y del Uribismo (negro) entre 2016 y 2014. El eje horizontal (cero) representa la ausencia de cambios en el número de votantes entre plebiscito y presidenciales. Valores por encima de cero sugieren que en determinado departamento se ganaron votos entre 2014 y 2016. Valores por debajo de cero sugieren que se perdieron votantes. 
Gráfico 3. Diferencias en número de votos a favor de las coaliciones santista y uribista entre 2016 y 2014

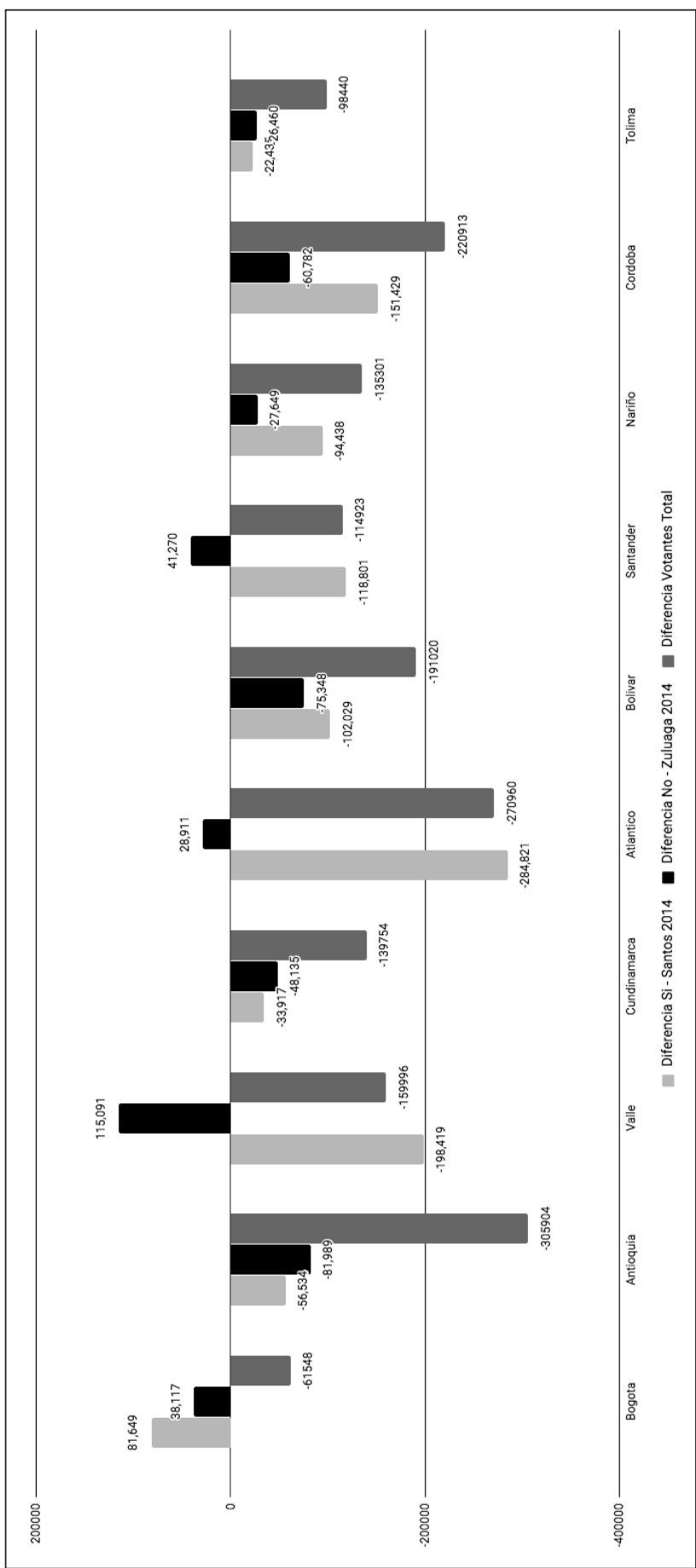

Fuente: Elaboración propia basada en datos de la Registraduría Nacional 
La coalición Santista no parece haber tenido ganancias en términos de votos en ninguno de estos departamentos, excepto en Bogotá, donde el Sí logró 81.649 votos más que Santos en las presidenciales de 2014. En varios departamentos clave, el No obtuvo muy buenos resultados. En Valle, Atlántico y Santander el No movilizó más votantes de los que el uribismo (su base principal) había logrado movilizar a favor de Zuluaga en 2014. De estos tres, concentrémonos en el Valle a manera de ilustración. Aunque allí (como en el Atlántico) se impuso el Sí, el No movilizó aproximadamente 115.000 votos más de los que había movilizado el uribismo en 2014. El Sí se impuso en este departamento en 2016, pero la coalición santista perdió casi 200.000 votos frente a su desempeño en las presidenciales dos años antes. El número de sufragantes total también fue menor en 2016, pero incluso teniendo ese decrecimiento en cuenta, puede decirse que la coalición de Santos sufrió pérdidas importantes en el Valle durante el plebiscito. Si recordamos que el plebiscito lo ganó el No por un estrecho margen de 53.894 votos, estas diferencias en movilización cobran renovada importancia.

En la recta final el Sí cambió un poco de tono y activó la maquinaria electoral. Sin embargo el No se movió más, se movió más rápido y se movió más efectiva y afectivamente, y ganó.

\section{LAS REPERCUSIONES DEL PLEBISCITO Y EL FUTURO DE LA PAZ NEGOCIADA}

En esta sección me concentro en identificar las principales implicaciones de la derrota del Sí y, en este contexto, discuto los desafíos políticos de la implementación de los acuerdos. El gobierno no tenía un mapa de ruta para este escenario de derrota; el 3 de octubre, todo el cronograma de implementación y verificación (que incluía monitoreo de las Naciones Unidas, listo para desplegarse el día siguiente) debió congelarse indefinidamente. Por su parte, los partidarios del No tampoco tenían propuestas concretas. En la etapa final previa al plebiscito, el No cambió de una postura de oposición tajante a los acuerdos hacia una solicitud de renegociación de ellos. Sin un plan claro, se vieron obligados a improvisar. Tras conocerse los resultados, las FARC y el gobierno ratificaron su compromiso con la negociación. El gobierno invitó a las fuerzas políticas al diálogo y nombró tres voceros para negociar con los partidarios del No, quienes hicieron lo propio. Solo tres días después, cuando el país todavía estaba tratando de procesar lo que significaban los resultados del plebiscito, una nueva noticia alteró el panorama político: el presidente Santos recibió el Nobel de la Paz. El anuncio le dio nuevos aires al gobierno y al frágil proceso. En esas semanas difíciles, el apoyo de la comunidad internacional al proceso de paz y al gobierno de Santos fue esencial para que el gobierno y los equipos negociadores navegaran un escenario doméstico que les era bastante hostil.

A lo largo de octubre, se dieron reuniones entre las partes para renegociar los acuerdos, hasta que a mediados de noviembre las FARC y el gobierno anunciaron 
un nuevo acuerdo. ${ }^{10}$ El texto de Juan Carlos Rodríguez Raga en este volumen identifica los momentos cronológicos fundamentales de la renegociación, los cuales culminaron en la firma de los nuevos acuerdos en Bogotá a finales de noviembre. Tras muchas discusiones y no pocas críticas, el gobierno y las FARC optaron por refrendar los nuevos acuerdos vía el Congreso, bajo el argumento de que el fallo de la Corte Constitucional que había autorizado el plebiscito aclaraba que la no aprobación popular no suponía automáticamente que estos fueran inválidos. En su fallo, la Corte autorizaba al Ejecutivo para que explorara formas alternativas de refrendar los acuerdos, dado el caso. Así fue.

\section{Implicaciones políticas de la derrota electoral del Sí}

El plebiscito supuso, entonces, la renegociación de los acuerdos, la adopción de un nuevo mecanismo para su refrendación (la vía parlamentaria) y la alteración de su cronograma de implementación para acomodar los retrasos. Estos cambios se sumaron y agravaron la inestabilidad política y jurídica en la que quedaron sumidos el país y el proceso de paz tras la victoria del No en las urnas. El panorama a finales de 2016 y de cara a la implementación era complejo y continuó siéndolo. En términos macro, la derrota electoral del Sí tuvo tres implicaciones para la reconfiguración del panorama político nacional. Primero, activó a los sectores de la sociedad civil que apoyaban el proceso de paz, quienes se movilizaron exigiendo un nuevo acuerdo. Segundo, la derrota electoral dejó al proceso de paz con un grave déficit de legitimidad, lo cual le puso más trabas a lo que ya era un proceso con muchos retos. Tercero, la campaña previa al plebiscito y la victoria del No, que el uribismo hizo suya, supusieron el arranque temprano de la campaña presidencial de 2018. A continuación discuto estos tres aspectos y con base en ellos, planteo algunos desafíos de cara a la implementación de los acuerdos.

La activación de la sociedad civil después del 2 de octubre fue significativa: los movimientos sociales y los jóvenes fueron protagonistas de varias movilizaciones a lo largo del mes en apoyo al proceso de paz. El 5 de octubre, tres días después del plebiscito, trece nutridas manifestaciones exigiendo la continuidad de las negociaciones con las FARC se llevaron a cabo en las principales ciudades de Colombia (Bogotá, Cali, Palmira, Medellín, Barranquilla, Cartagena, Manizales, Quibdó, Santa Marta, Riohacha, Bucaramanga, Neiva y Pasto). Este movimiento ciudadano fue liderado por organizaciones sociales, estudiantes, víctimas e indígenas con una consigna principal: \#AcuerdoYa. Según la Fundación Ideas para la Paz (2016), entre el 5 y el 25 de octubre hubo al menos una movilización social diaria en algún punto del país en apoyo a los acuerdos, para un total de 54 a lo largo del mes. Esta activación de la sociedad civil, hasta ahora un tanto

10 Para un resumen de los cambios al nuevo acuerdo, ver Alto Comisionado para la Paz (2016); para un análisis más político de lo que cambió, véase “Los cambios en el Acuerdo Final, uno a uno" (La Silla Vacía 2016, 15 de noviembre). 
alejada del proceso de paz, no es poca cosa: en ese momento, supuso un capital político importante de apoyo al proceso. El reto a largo plazo es que las fuerzas que lograron coordinar en octubre se mantengan activas o al menos vuelvan a hacerse sentir de ser necesario. Hacia el futuro, el gobierno seguramente buscará recurrir a este capital nuevamente durante la dura fase de implementación. Como veremos a continuación, este apoyo puede llegar a ser definitivo, dado el déficit de legitimidad que tiene hoy por hoy el proceso de paz.

Una de las consecuencias más graves de los resultados del plebiscito fue que dejaron al proceso de paz con un considerable déficit de legitimidad. Para salvar el proceso, los equipos negociadores y el gobierno optaron por la refrendación vía el Congreso. Esta decisión es entendible en ese contexto, y es legal: la Corte Constitucional previó mecanismos de refrendación alternativos, y el Congreso es el órgano representativo. Sin embargo, la refrendación por la vía legislativa no es vista como legítima por amplios sectores en Colombia. Para algunos, el Congreso es una institución desprestigiada que ha sido muy cuestionada por escándalos de corrupción. Otros consideran que estos legisladores no fueron elegidos para decidir sobre un cambio constitucional tan crucial como fue la aprobación de los acuerdos de paz de La Habana; era necesaria una Asamblea Constituyente $u$ otro plebiscito. Tras cuatro años de insistir en la necesidad y las bondades de la refrendación a través del plebiscito, es difícil sostener de forma convincente frente a grupos de apoyo decisivo y a una opinión pública polarizada que se va a desconocer esa votación, aun si la victoria fue por un margen apretado. Estas críticas las comparten incluso sectores que han apoyado el proceso desde el principio. Por estas razones subsiste el mal sabor tras una maniobra que no cuadra del todo en un momento particularmente delicado.

El gobierno de Santos hizo un esfuerzo importante por adelantar un proceso de paz de forma cuidadosa, incorporando las lecciones centrales de las experiencias de negociación anteriores y lo hizo con éxito hasta conseguir la firma de los acuerdos. Sin embargo, el gobierno perdió la apuesta por la refrendación popular en la recta final, y el costo político de desconocer ese resultado ha sido y continuará siendo enorme. Los partidarios del No y los críticos del gobierno han puesto mucho énfasis en la contradicción inherente al desconocimiento de los resultados del plebiscito, y continuarán recordándole esto a la opinión pública de cara a las elecciones presidenciales que se avecinan. La situación no es fácil, pues la derrota electoral del Sí el 2 de octubre de 2016 supone un problema estratégico de cara a la campaña presidencial, pero también socava el apoyo político que el proceso necesita con miras a su implementación.

El siguiente paso en la implementación es la aprobación de los paquetes legislativos que dan vida a los acuerdos, proceso que va a requerir de todo el capital político del gobierno, escaso últimamente. El primer escollo apareció durante la aprobación del Acto Legislativo por el cual se estableció el fast track, como se le conoce al procedimiento legislativo especial para acortar los tiempos de trámite de las reformas constitucionales relacionadas con la implementación de los acuerdos. El fast track, aprobado en el Congreso en diciembre de 2016, 
prevee que los proyectos de ley relacionados con la paz tengan menos debates legislativos $\mathrm{y}$, originalmente, garantizaba también que tuvieran que votarse en bloque y que cualquier modificación requiriese del aval del gobierno. La Corte Constitucional declaró inconstitucionales estos últimos dos apartes, argumentando que eran contrarios a la separación de poderes. En la práctica, esto significa que los debates serán más prolongados y que el contenido podrá ser más fácilmente modificado por el Congreso. La implementación tendrá que ser más ampliamente debatida — tal vez haya ahí una oportunidad para legitimar las reformas (Guarín 2017). En cualquier caso, mantener su espíritu va a requerir aún más esfuerzos.

Otra consecuencia de la victoria del No en el plebiscito por la paz fue el fortalecimiento del uribismo y de sectores de la derecha conservadora de cara a la campaña presidencial de 2018. Una de las estrategias de campaña del No, como vimos, fue hacer del plebiscito un referendo sobre la gestión del presidente Santos. En este sentido, el plebiscito funcionó como "ejercicio de calentamiento" para las presidenciales del próximo año. El eje central de la contienda política serán los acuerdos: con el uribismo fortalecido y todavía en oposición a la paz negociada, está en juego la implementación y que se respete lo pactado.

\section{Algunos desafíos a la consolidación de la paz negociada}

Así las cosas, el proceso de paz con las FARC entró en su etapa de implementación en medio de un ambiente político enrarecido y cuestionado por sectores importantes. A futuro son numerosos los retos de la implementación y de la consolidación de la paz. En el corto y mediano plazo vale la pena resaltar tres.

Primero: cómo subsanar el déficit de legitimidad de los acuerdos. Esto tal vez pueda lograrse a través del proceso de debate y socialización de las más de cincuenta reformas y actos legislativos que se discutirán en los meses siguientes para reformar el marco legal existente y crear las instituciones que darán vida a los acuerdos. Otra opción, independiente o complementaria a la anterior, sería la refrendación popular de las reformas más adelante.

Segundo: el proceso de paz necesita de una estrategia para sobrevivir a la campaña presidencial de 2018. La etapa inicial de implementación de los acuerdos coincide con una campaña política donde varios de los actores le son hostiles. Como vimos, la victoria del No fortaleció a sectores uribistas y conservadores que obtendrán réditos políticos importantes de oponerse a los acuerdos y desprestigiarlos. Va a ser difícil lidiar con los imprevistos, los errores (inevitables), la controversia y las realidades de un proceso de esta envergadura en medio de una campaña política.

Tercero: la falta de consenso amplio a favor de la paz complica uno de los interrogantes más grandes: cómo hacer realidad la paz territorial. Una de las premisas básicas de los acuerdos es la necesidad de que la paz sea una paz 
territorial; es decir, que no sea una imposición centralizante, dictada desde Bogotá, sino que sea fruto de y responda a los escenarios locales y las regiones más afectadas por el conflicto. Materializar esta premisa supone superar una de las dificultades endémicas más grandes de Colombia: la presencia diferenciada del Estado a lo largo del territorio nacional. Este proceso de paz es el décimo que los colombianos emprendemos recientemente (sin contar experiencias previas a finales de los 1950 y comienzos de los 1960). ${ }^{11}$ Todos los intentos anteriores, en su mayoría fallidos, han venido acompañados por programas e iniciativas que buscaron fortalecer al Estado. El problema central según Claudia López (2016) es que más allá de las diferencias entre estos programas, las élites en el centro se han articulado históricamente con las unidades territoriales subnacionales vía redes clientelistas que demandan, extraen y circulan recursos (materiales y simbólicos) de manera opresiva y a menudo violenta. En el pasado, las élites políticas y económicas colombianas, que en muchas ocasiones se benefician del status quo, no han demostrado voluntad política de cambiar el modelo (Robinson 2017). Hacer realidad la paz territorial requiere dar acceso a tierras, renunciar a privilegios, redistribuir recursos, priorizar inversión en zonas de conflicto, aceptar la participación política de las FARC y negociar. Estos son "sapos" que muchos no se quieren tragar. Consolidar la paz negociada con las FARC también requiere de un Estado fuerte que pueda enfrentar las amenazas que subsisten en forma de bandas armadas (conocidas como BACRIM) vinculadas con actividades criminales y con el tráfico de drogas. Romper ese círculo y fortalecer el Estado repensando la relación centro-región en Colombia es un inmenso desafío. Sin un consenso amplio alrededor de los acuerdos de paz, parece un objetivo particularmente esquivo.

\section{CONCLUSIONES}

El 2016 fue un año histórico para Colombia, al cerrarse el proceso de negociaciones con las FARC y firmarse los acuerdos de paz de La Habana. En este texto presenté un análisis de los pormenores del cierre de las negociaciones, concentrándome en proponer claves para entender la victoria del No en el plebiscito que pretendía refrendar los acuerdos por la vía popular. Mi argumento central es que para entender la apretada victoria del No es necesario pararse en la intersección de lo estructural (los niveles de pobreza, inequidad, presencia estatal e incidencia del conflicto a nivel municipal) con lo político (en especial, las características de la campaña electoral). A pesar de los resultados del plebiscito, el proceso de paz siguió adelante tras la refrendación de los acuerdos de paz a través del Congreso. La derrota del Sí reconfiguró el panorama político nacional fortaleciendo políticamente a los sectores que apoyaron al No, especialmente al uribisimo. Más allá de lo coyuntural, la falta de consenso frente a la paz negociada dejó al proceso de paz con un déficit de legitimidad política que 
plantea muy serios desafíos a la implementación y a la consolidación de los acuerdos de La Habana.

\section{REFERENCIAS}

Alto Comisionado para la Paz. 2016, 23 de julio. “ABC Preguntas y Respuestas: Sobre enfoque de género en los acuerdos de paz." Recuperado el 10 de junio de 2017 de http:/ / equipopazgobierno.presidencia.gov.co/prensa/declaraciones/Paginas/abc-preguntas-respuestas-enfoque-genero-acuerdos-paz-habana-colombia.aspx

Alto Comisionado para La Paz. 2016, 13 de noviembre. "Notas sobre los cambios, ajustes y precisiones del nuevo acuerdo final para la terminación del conflicto y la construcción de la paz estable y duradera." Recuperado el 7 de junio de 2017 de http:/ / www.altocomisionadoparalapaz.gov.co/procesos-y-conversaciones/Documentos\%20compartidos/Cartilla-Cambios-Nuevo-Acuerdo-web.pdf

Alvarez Vanegas, Eduardo y Juan Carlos Garzón Vergara. 2016. Votando por la paz: Entendiendo la ventaja del "No". Bogotá: Fundación Ideas para La Paz.

Botero, Sandra. 2016, 5 de octubre. "Colombianos divididos ante la paz." Recuperado el 25 de mayo de 2017 de http://sites.utexas.edu/llilas-benson-alumni/2016/10/05/colombianos-divididos-ante-la-paz/

Caicedo Ortíz, Julián Andrés. 2015. “Abstención electoral y voto en blanco en la consolidación democrática colombiana." En Elecciones en Colombia, 2014. ¿Representaciones fragmentadas?, editado por Fredy Barrero y Margarita Batlle. Bogotá: Konrad Adenauer Stiftung, 45-87.

Caracol Radio. 2016, 8 de agosto. "Así están las encuestas sobre el plebiscito por la paz." Recuperado el 4 de junio de 2017 de http://caracol.com.co/radio/2016/08/09/politica/1470695746_684954.html

El Colombiano. 2016, 19 de diciembre. "Consejo de Estado dice que hubo engaño en campaña del No." Recuperado el 21 de junio de 2017 de http://www.elcolombiano.com/ colombia/acuerdos-de-gobierno-y-farc/consejo-de-estado-dice-que-hubo-engano-en-campana-del-no-al-plebiscito-MY5607952

Fergusson, Leopoldo y Carlos Molina. 2016, 4 de octubre. “Un Vistazo a los Resultados del Plebiscito." Recuperado el 6 de junio de 2017 de http://lasillavacia.com/blogs/ un-vistazo-los-resultados-del-plebiscito-58200

Fundación Ideas para La Paz. 2016. "Radiografía del plebiscito y el pos-plebiscito." Recuperado el 4 de junio de 2017 de http:/ / www.ideaspaz.org/especiales/posplebiscito/

Guarín, Sergio. 2017, 18 de abril. “Desafío al Fast Track." Recuperado el 9 de junio de 2017 de http:/ /lasillavacia.com/blogs/desafio-al-fast-track-60998

Karl, Robert A. 2017. Forgotten Peace: Reform, Violence and the Making of Contemporary Colombia. Oakland: University of California Press.

La República. 2016, 6 de octubre. “'Estábamos buscando que la gente saliera a votar verraca': Juan C. Vélez." Recuperado el 1 de junio de 2017 de http:/ / www.elcolombiano.com/ colombia/acuerdos-de-gobierno-y-farc/entrevista-a-juan-carlos-velez-sobre-la-estrategia-de-la-campana-del-no-en-el-plebiscito-CE5116400

La Silla Vacía. 2016, 3 de octubre. "Así falló la maquinaria del Sí." Recuperado el 1 de junio de http:/ /lasillavacia.com/historia/asi-fallo-la-maquinaria-del-si-58189

La Silla Vacía. 2016, 15 de noviembre. "Los cambios en el Acuerdo Final uno a uno." Recuperado el 9 de junio de 2017 de http:/ /lasillavacia.com/hagame-el-cruce/los-cambiosen-el-acuerdo-final-uno-uno-58739

Liendo, Nicolás y Jessica M. Braithwaite. 2016, 26 de septiembre. “¿Sí o No? ¿Quién apoya el proceso de paz en Colombia?" Recuperado el 4 de junio de 2017 de http:/ / www.asuntosdelsur.org/opinion/si-o-no-quien-apoya-el-proceso-de-paz-en-colombia

López, Claudia. 2016. Adiós a las Farc. ¿Y ahora, que? Bogotá: Debate. 
López Montaño, Cecilia y Nicolás Cueter. 2016, 30 de diciembre. “¿Por qué Santos sí pudo dialogar con las Farc?" Recuperado el 1 de junio 2017 de http:/ /www.eltiempo.com/ politica/proceso-de-paz/procesos-de-paz-en-colombia-44168

Muñoz, Juan Sebastián y Juan David Herreño. 2016, 13 de octubre. "País(es) Divergentes: radiografía del plebiscito." Recuperado el 2 de junio de 2017 de http:/ / colombia2020. elespectador.com/pais/paises-divergentes-radiografia-del-plebiscito

Pizarro Leongómez, Eduardo. 2017. Cambiar el futuro: Historia de los procesos de paz en Colombia 1981-2016. Bogotá: Debate.

Robinson, James. 2017. “Colombia: el derrumbe parcial." Recuperado el 5 de junio de 2017 de http:/ / colombia2020.elespectador.com/pais/colombia-el-derrumbe-parcial

Semana. 2016, 17 de agosto. "Ideología de género: una estrategia para ganar adeptos por el No al plebiscito." Recuperado el 1 de junio de 2017 de: http:/ / www.semana.com/nacion/ articulo/ideologia-de-genero-una-estrategia-para-ganar-adeptos-por-el-no-al-plebiscito $/ 488260$

Semana. 2016, 8 de octubre. “La estrategia del Sí tuvo muchos desaciertos: Francisco Gutiérrez." Recuperado el 1 de junio de 2017 de http:/ / www.semana.com/nacion/articulo/francisco-gutierrez-habla-de-la-estrategia-del-si-en-el-plebiscito/498218

Semana. 2016, 29 de octubre. "Cristianos: ¿el poder decisorio en la política?" Recuperado el 9 de junio de 2017 de http:/ / www.semana.com/nacion/articulo/religion-inclina-la-balanza-politica-en-colombia/502530

Semana, 2016, 19 de diciembre. "'Las mentiras' de las campañas del No, según el Consejo de Estado." Recuperado el 10 de junio de 2017 de http:/ / www.semana.com/nacion/ articulo/el-consejo-de-estado-dice-que-se-le-mintio-al-electorado-en-campanas-delno/510040

Semana. 2016, 23 de diciembre. "El Rompecabezas emocional de la paz." Recuperado el 3 de junio de 2017 de http://www.semana.com/nacion/articulo/plebiscito-por-la-paz-triunfo-la-indignacion-por-encima-de-la-esperanza/510390

Urna de Cristal. 2013, 17 de junio. “¿Qué significa la frase 'nada está acordado hasta que todo esté acordado'?" Recuperado el 10 de junio de 2017 de http:/ / www.urnadecristal.gov. co/video/qu-significa-frase-nada-est-acordado-hasta-que-todo-est-acordado

Wills Otero, Laura y Carlos Andrés Hoyos. 2016. "Colombia en 2015: Paz, elecciones regionales y relaciones entre las ramas del Poder Público." Revista de Ciencia Política 76(1): 75-101.

Sandra Botero es profesora en la Facultad de Ciencia Política, Gobierno y Relaciones Internacionales de la Universidad del Rosario en Bogotá. Es historiadora de la Universidad Nacional de Colombia, con una maestría en estudios latinoamericanos de la Universidad de Texas en Austin y un doctorado en ciencia política de la universidad de Notre Dame. Su tesis doctoral recibió el premio 2016 a la mejor disertación de la Law and Society Association. Sus dos publicaciones más recientes son: "Agents of Neoliberalism? High courts, Legal Preferences and Rights in Latin America" (capítulo en volumen editado para University of Pennsylvania Press 2017) y “Judicial Impact and Court-Promoted monitoring in Argentina (Comparative Politics 2018). email: sandra.boteroc@urosario.edu.co 